\title{
FORMAÇÃO INTEGRAL: AS CONCEPÇÕES PRESENTES NAS CASAS FAMILIARES RURAIS DO PARANÁ
}

\author{
Integral Education: the concepts present in the Rural Family Houses in Paraná State
}

\author{
Formación Integral: los Conceptos Presenta en Hogares de Familia Rural Paraná
}

\author{
Luciane Maria Serrer de Mattos ${ }^{1}$ \\ Maria de Lourdes Bernartt ${ }^{2}$
}

\begin{abstract}
RESUMO: O texto é fruto de estudos e discussões realizados no Programa de Pós-Graduação em Desenvolvimento Regional da Universidade Tecnológica Federal do Paraná, campus Pato Branco. Tem por objetivo refletir sobre as concepções de formação integral presentes nas Casas Familiares Rurais do Estado do Paraná. Busca-se compreender a concepção de formação integral que sustenta a Pedagogia da Alternância, praticada nas Casas Familiares Rurais, e analisar se esta se aproxima ou distancia da concepção explicitada pelas Diretrizes da Educação Profissional do Estado do Paraná. A reflexão é de suma importância, pois os profissionais que trabalham nas Casas Familiares Rurais do Paraná possuem a orientação de colocar em prática os pressupostos que orientam a Pedagogia da Alternância, sem deixar de seguir as Diretrizes Curriculares Estaduais. Após a explicitação das concepções de formação integral na Pedagogia da Alternância e das Diretrizes da Educação Profissional, se analisa as bases epistemológicas que as sustentam concluindo que elas se distanciam porque a primeira situa-se em bases idealistas e a segunda em bases materialistas.
\end{abstract}

Palavras-chave: Formação Integral. Pedagogia da Alternância. Casas Familiares Rurais.

\section{INTRODUÇÃO}

O texto é fruto de estudos e discussões realizados no Programa de Pós-Graduação em Desenvolvimento Regional da Universidade Tecnológica Federal do Paraná (UTFPR), campus de Pato Branco. Tem por objetivo refletir sobre as concepções de formação integral presentes nas Casas Familiares Rurais do Estado do Paraná.

A primeira Maison Familiale Rurale foi criada em 1935, na França. GarciaMarirrodriga e Calvó (2010) ressaltam que, nessa época, a educação formal tinha uma proposta de ensino voltada para o meio urbano, incompatível com a realidade dos jovens do

\footnotetext{
${ }^{1}$ Pedagoga, professora da Educação Básica, mestranda no Programa de Pós-Graduação da Universidade Tecnológica Federal do Paraná - Câmpus Pato Branco.

${ }^{2}$ Doutora em Educação, Docente do Programa de Pós-Graduação em Desenvolvimento Regional da UTFPR -

Câmpus Pato Branco.
} 
campo. Além disso, tais jovens tinham que deixar as atividades nas propriedades rurais para prosseguirem seus estudos.

Diante dessa problemática, agricultores, líderes sindicais e religiosos criaram uma associação visando possibilitar aos jovens um aprendizado teórico/prático sem a necessidade de abandonar suas atividades na propriedade rural. Assim surgiu a primeira Casa Familiar Rural (CFR) com sistema de ensino realizado de forma alternada. Os jovens passavam três semanas nas propriedades e uma semana, em regime de internato, nas dependências da igreja.

Através da associação, se constrói uma pedagogia que parte da realidade dos jovens do campo, possibilitando a construção de seus conhecimentos a partir do concreto vivido e cujos tempos de formação alternam-se entre escola e meio sócio familiar. Com essa experiência, nasceu toda uma estrutura pedagógica, conhecida por Pedagogia da Alternância (ESTEVAM, 2012).

A Pedagogia da Alternância situa-se, portanto, no contexto da Educação do Campo e têm por objetivo, de acordo com Gimonet (2007), a formação integral do jovem e o desenvolvimento do meio em que ele vive.

Sendo a formação integral um dos objetivos da Pedagogia da Alternância, essa investigação objetiva suscitar reflexões sobre as concepções de formação integral presentes nas CFRs do Estado do Paraná.

De acordo com Estevam (2012), as CFRs começaram a funcionar no Paraná em fins dos anos 1980. Atualmente o Estado totaliza 46 CFRs, administradas por uma Associação de famílias dos jovens que as frequentam e Secretaria do Estado da Educação do Paraná além de serem coordenadas pela Associação Regional das Casas Familiares Rurais do Sul do Brasil (ARCAFAR-Sul), com sede no município de Barracão - PR.

A Secretaria de Estado da Educação do Paraná mantem os professores das diversas áreas do conhecimento que atuam nas CFRs, subsidia o trabalho que deve atender as Diretrizes e normas legais bem como, vincula cada CFRs a um de seus estabelecimentos de ensino que se responsabiliza pelo registro dos históricos escolares dos jovens.

Observa-se, portanto, que apesar de possuírem dinâmica própria, baseada na Alternância, as CFRs estão subordinadas ao Sistema Estadual de Educação comum a todos os estabelecimentos formais de educação. Nesse contexto, os profissionais que trabalham nas CFRs do Paraná são orientados a colocar em prática os pressupostos da Pedagogia da Alternância, sem deixar de seguir as Diretrizes Estaduais.

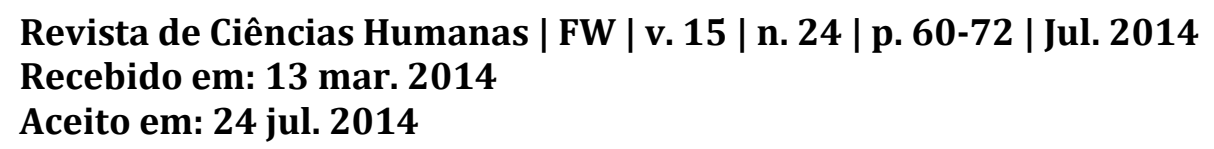


Visando atender o objetivo proposto, aborda-se sobre a formação integral concebida na Pedagogia da Alternância e nas Diretrizes da Educação Profissional do Estado do Paraná bem como se analisa as bases epistemológicas que as sustentam delineando aproximações e/ou distanciamentos.

\section{FORMAÇÃO INTEGRAL NA PEDAGOGIA DA ALTERNÂNCIA}

O conceito de Formação Integral é recorrente em textos da área educacional, no entanto, pouco se discute sobre suas matrizes ideológicas. Em geral, os autores tratam a formação integral como um objetivo a ser alcançado, sem esclarecer as diferentes concepções e práticas pedagógicas que se pautam a partir desses termos.

Gallo (2002) afirma que a formação integral interessou desde reformistas católicos a socialistas ateus, tamanha a repercussão do conceito. De acordo com as inspirações teóricas, a forma como veem e concebem o mundo, pesquisadores da educação apresentam diferentes concepções de Formação Integral, cujas características geram práticas diversas. Isso significa que várias correntes do pensamento educacional se interessaram pelos princípios da educação integral e as interpretaram de diferentes formas, respaldando diferentes práticas escolares.

A formação integral também interessou os idealizadores das CFRs que reconheciam a necessidade dessa formação para que os jovens pudessem contribuir com o desenvolvimento do meio rural. Para tanto, os jovens precisavam de conhecimentos teóricos, científicos e práticos relacionados ao seu meio e que lhes possibilitassem assumir a responsabilidade em todos os aspectos da vida coletiva.

As CFRs têm como objetivos, segundo Garcia-Marirrodriga e Calvó (2010), a formação integral do jovem e o desenvolvimento local por meio da Alternância e da Associação das famílias e sujeitos locais.

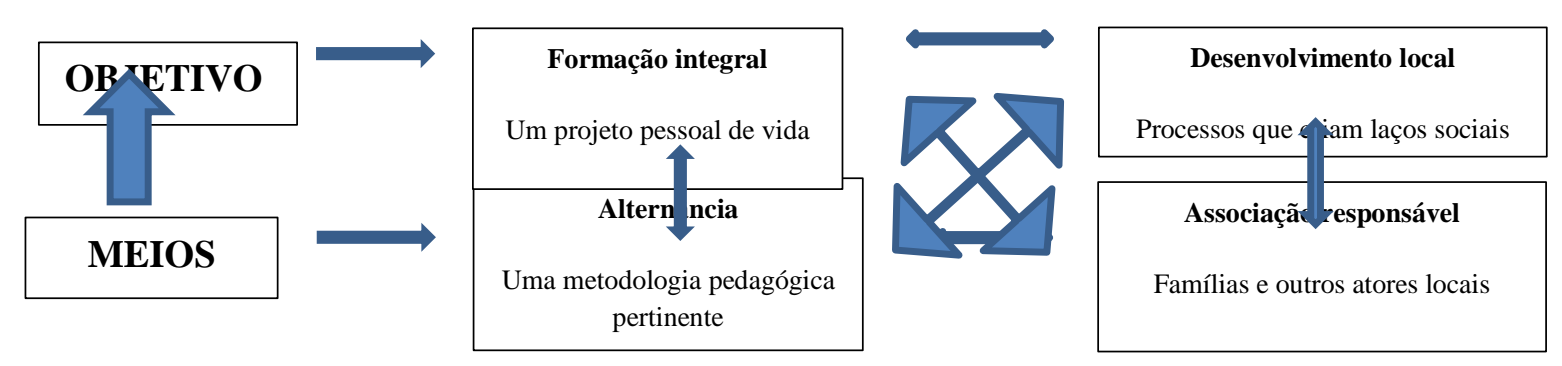

FIGURA 1 - Os Quatro Pilares dos CEFFAs. adaptado de GARCIA-MARIRRODRIGA; CALVÓ, 2010.

Revista de Ciências Humanas | FW | v. 15 | n. 24 | p. 60-72 | Jul. 2014 
Observa-se, na figura 1, que os objetivos e os meios formam os pilares que sustentam a Pedagogia da Alternância e fazem dela uma metodologia diferenciada e pensada para atender às necessidades do jovem, o desenvolvimento do meio em que vive e a participação da comunidade local.

Sendo um dos objetivos a formação integral, a Pedagogia da Alternância procura articular o conhecimento dos jovens do campo com o conhecimento científico, através da alternância do tempo e do espaço. Os estudantes passam duas semanas aplicando os conhecimentos adquiridos nas suas propriedades junto à família e uma semana na CFR para socialização das práticas, dos desafios e aquisição de novos conhecimentos.

Esse processo, de acordo com Pereira (2005), permite a valorização de aspectos humanos e espirituais, além da consolidação de hábitos sociais, a superação do individualismo e a garantia de uma formação global pelas reflexões e análises da realidade.

Essa forma de trabalho visa romper com a dicotomia teoria/prática, valorizando tanto os saberes científicos quanto populares. Além disso, procura demonstrar que a educação acontece também no meio em que o jovem vive e que as aprendizagens ali efetivadas são complementadas por aquelas que ocorrem na escola.

A Pedagogia da Alternância se inscreve, segundo Gimonet (2007), na lógica piagetiana de praticar e compreender. Nesse sentido, praticar significa agir, experienciar enquanto compreender é a conceitualização que se pode extrair da prática. Por isso, as CFRs priorizam a experiência familiar, social e profissional como fonte de conhecimento, ponto de partida e chegada do processo de aprendizagem.

Isso significa que a proposta de formação dos jovens parte da realidade vivida e avança, progressivamente, para o conhecimento abstrato. Eles percebem a relação entre o que fazem em seu meio sócio familiar e os estudos propostos. Observa-se que todos os saberes são valorizados e por diversos formadores como as famílias, as pessoas da comunidade e os vários parceiros das CRFs. Esses saberes são legitimados quando na produção do Plano de Formação que é “a estruturação, a priori, dos fins de formação dos jovens e define como está organizada a proposta de alternância" (ESTEVAM, 2012, p. 90).

O Plano de Formação prevê os conteúdos que os jovens terão durante o período de formação, integrando os saberes dos diferentes sujeitos que contribuem para o processo bem como procura conciliar o programa oficial com o projeto da CFR. 
De acordo com Pereira (2005), o Plano de Formação deve considerar três áreas relacionadas às dimensões da pessoa humana: intelectual, afetiva e a socioeconômica. $\mathrm{O}$ autor define a área intelectual como o centro da estrutura, responsável por reger a vida da pessoa e sustentar as demais áreas. A área afetiva é responsável pela compreensão de valores, sentimento e crenças e a socioeconômica pelo aprendizado ocupacional que impulsiona o jovem para o trabalho eficiente e melhora sua qualidade de vida.

Nesta concepção de educação, a lógica centra-se no jovem contextualizado e a formação integral compreende quatro aspectos (ROCHA, 2007): desenvolvimento de todas as potencialidades humanas; integração de conhecimentos e disciplinas em abordagens interdisciplinares, transdisciplinares e transversais; articulação de aprendizagens a partir de projetos temáticos e, tempo para que o ensino seja organizado num conjunto de experiências diversificadas e educativas na escola e no meio familiar.

Além desses aspectos, Ambrósio (2002) destaca que a formação dos jovens que aproveitam toda a vida social como espaço educativo deve assentar-se em cinco pilares: formação que visa a cidadania ativa, que concede a cada sujeito o empowerment, contínua para aquisição de competências, multicultural e reflexiva a partir das capacidades múltiplas.

Portanto, a Pedagogia da Alternância busca o desenvolvimento dos conhecimentos através do diálogo dos saberes e, como consequência, o compromisso do jovem com seu meio, formando sua personalidade e lhe capacitando para a ação.

\section{FORMAÇÃO INTEGRAL NAS DIRETRIZES DA EDUCAÇÃO PROFISSIONAL DO ESTADO DO PARANÁ}

As Diretrizes da Educação Profissional do Paraná (2006) são uma referência para a elaboração de currículos de cursos técnicos, posicionada a favor da classe que vive do seu trabalho. Portanto, é um documento que caracteriza uma política de Estado comprometida com a emancipação da classe trabalhadora. Este documento foi construído, coletivamente, por professores da rede estadual após amplo debate sobre a identidade do Ensino Médio. Também orientam o trabalho nas CFRs que ofertam o Ensino Médio Profissionalizante.

O compromisso expresso nas Diretrizes da Educação Profissional (2006) de emancipar a classe trabalhadora se materializa na clara pretensão de superar a dualidade educacional presente ao longo da história da educação brasileira. Segundo Saviani (2007), aos filhos da

Revista de Ciências Humanas | FW | v. 15 | n. 24 | p. 60-72 | Jul. 2014

Recebido em: 13 mar. 2014

Aceito em: 24 jul. 2014 
classe dominante foi oferecida uma educação intelectualizada para que prosseguissem em estudos superiores e se formassem para serem os dirigentes. Ao contrário, à classe trabalhadora foi ofertada uma educação voltada para a integração ao processo produtivo, enfatizando os aspectos operacionais em detrimento dos intelectuais.

Para superar a formação da classe trabalhadora restrita ao mercado de trabalho é necessário que uma formação integral seja garantida aos jovens de modo que se articulem conhecimentos gerais a específicos, sob os eixos do trabalho, ciência, tecnologia e cultura. As Diretrizes assumem, também, o compromisso com a formação humana dos alunos, "a qual requer a apreensão dos conhecimentos científicos, tecnológicos e históricos sociais pela via escolarizada" (PARANÁ, 2006, p. 20).

Para as Diretrizes da Educação Profissional, assumir o compromisso com a formação integral dos jovens implica adotar o trabalho como princípio educativo. Isso exige o reconhecimento de que, em cada modo de produção, os grupos sociais possuem demandas diferenciadas de educação.

Segundo Saviani (2007), com o desenvolvimento dos modos de produção e, sobretudo, com a apropriação privada da terra, ocorreu à divisão do trabalho, dos homens em classes e na educação. A educação dividiu-se em duas modalidades distintas e separadas: uma para a classe proprietária, identificada como a educação dos homens livres, e outra para a classe não proprietária, identificada como a educação dos escravos e serviçais.

A Revolução Industrial pôs em questão a separação entre instrução e trabalho produtivo, forçando a escola a ligar-se ao mundo da produção. Assim, a burguesia concebeu e realizou a educação a partir da divisão dos homens em dois grandes campos: profissões manuais e profissões intelectuais.

Essa breve retomada histórica é importante para se afirmar o papel fundamental da escola de nível médio: recuperar essa relação entre o conhecimento e a prática do trabalho.

Tomar o trabalho como princípio educativo, se por um lado implica uma
metodologia que permite analisar os projetos educativos a partir das demandas dos
processos social e produtivo, os quais, no capitalismo, implicam exploração dos
trabalhadores, por outro lado, aponta a possibilidade da construção de projetos
alternativos que atendam às necessidades dos que vivem do trabalho (PARANÁ,
2006, p. 23).

A escola é uma instituição cujo papel consiste na socialização do saber sistematizado; é o lugar de aprender a interpretar o mundo para poder transformá-lo.

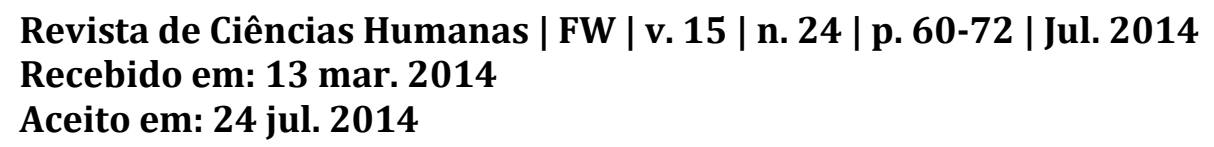


Atribuir à escola o papel de responsável pelo desenvolvimento de competências é uma forma sutil de exclusão dos que vivem do trabalho; portanto, cabe à escola oportunizar ao aluno o desenvolvimento das capacidades cognitivas, afetivas e psicomotoras articulando o trabalho intelectual ao mundo do trabalho.

Dessa forma, as Diretrizes explicitam que adotar o trabalho como princípio educativo não significa se deixar dominar pelas propostas que articulam escola e produção ou à proposta das escolas ativas.

As Diretrizes da Educação Profissional inspiram-se na concepção gramsciana de escola unitária que propõe "a tarefa de inserir os jovens na atividade social, após tê-los levado a certo grau de maturidade e capacidade, à criação intelectual e prática e a certa autonomia na orientação e na iniciativa" (GRAMSCI, 1968, p. 121). O Ensino Médio assumiu nessa perspectiva grande importância para a formação intelectual e moral e serviu de base para a especialização posterior, tanto no Ensino Superior quanto no processo produtivo.

Gramsci criticava o modelo de escola profissional que apenas cumpria a função de eternizar as estratificações de classes e a predestinação da maioria ao trabalho alienante, sob falsos princípios democráticos:

\footnotetext{
Na escola atual, em função da crise profunda da tradição cultural e da concepção da vida e do homem, verifica-se um processo de progressiva degenerescência: as escolas de tipo profissional, isto é, preocupadas em satisfazer interesses práticos imediatos, predominam sobre a escola formativa, imediatamente desinteressada. O aspecto mais paradoxal reside em que este novo tipo de escola aparece e é louvado como democrático, quando na realidade, não só é destinado a perpetuar as diferenças sociais, como ainda a cristalizá-las em formas chinesas (GRAMSCI, 2001, p. 49).
}

Neste sentido, as escolas ocupam um papel de suma importância na sociedade capitalista na medida em que podem tanto contribuir para a formação do aluno trabalhador que interessa ao capital quanto apontar uma formação omnilateral de sujeitos capazes de atuarem na superação dessa sociedade.

O conceito de omnilateralidade fundamenta as proposições pedagógicas presentes nas Diretrizes da Educação Profissional. Manacorda (2008) define a omnilateralidade como a chegada histórica do ser humano a uma totalidade de capacidades produtivas e, ao mesmo tempo, a uma totalidade de capacidades em que deve considerar o gozo de bens espirituais e materiais de que o trabalhador tem sido excluído em consequência da divisão do trabalho. 
Portanto, a omnilateralidade se contrapõe à formação unilateral provocada pelo trabalho alienado e pela divisão social do trabalho. Ela implica, pois, a integração das dimensões fundamentais da vida que respaldam a prática social: o trabalho, a ciência e a cultura. O trabalho compreendido como realização humana e como prática econômica; a ciência compreendida como os conhecimentos que possibilitam o contraditório avanço produtivo e a cultura, que compreende os valores éticos e estéticos que orientam a conduta dos seres humanos.

Neste sentido, a proposta político-pedagógica das Diretrizes da Educação Profissional (2006) aponta para a necessidade da formação integral do ser humano, não podendo o desenvolvimento ficar restrito à dimensão lógico-formal ou às funções ocupacionais do trabalho.

A formação integral reúne os vários aspectos constitutivos do homem que se desenvolve através das dimensões pedagógicas, das relações sociais e produtivas, com a finalidade de produzir as condições necessárias à existência.

\section{FORMAÇÃO INTEGRAL NAS CASAS FAMILIARES RURAIS DO PARANÁ}

As CFRs obtiveram apoio institucional do governo paranaense a partir dos primeiros anos da década de 1990. A parceria consiste em vincular as CFRs a um estabelecimento estadual que se responsabiliza pelo registro do histórico escolar dos jovens e pela cedência, através de processo específico de escolha coordenado pelos Núcleos Regionais de Educação, de professores das diversas áreas do conhecimento. Ou seja, os jovens são alunos e os professores funcionários da rede estadual de ensino, orientados de acordo com a legislação emitida pela Secretaria de Estado da Educação.

Em contrapartida, as CFRs possuem as Associações de Pais que auxiliam na manutenção das casas e possuem grande poder decisório.

Observa-se que a relação entre o Estado e as CFRs é complexa e delicada. As CFRs podem perder sua essência ao atenderem a todas as orientações e determinações do Estado, pois a Pedagogia da Alternância é um modelo pensado para os jovens do campo que se contrapõe ao modelo de ensino regular proposto nos demais estabelecimentos de ensino da rede estadual. 
O conceito de formação integral dos jovens do campo apresenta diferentes concepções teóricas nas propostas das CFRs e Diretrizes da Educação Profissional do Paraná.

A formação integral na Pedagogia da Alternância, adotada pelas CFRs inspira-se nas ideias de Piaget (1977). Para o autor a educação consiste em oportunizar ao aluno a construção de seu conhecimento na e pela sua atividade prática. Destaca que as aprendizagens realizadas pelo indivíduo são qualitativamente superiores àquelas em que há a interferência do professor. O importante é aprender a aprender e não apropriar-se dos conhecimentos historicamente produzidos.

Destaca Ambrósio (2002) que a Formação Integral, na Pedagogia da Alternância, pressupõe o desenvolvimento dos aspectos intelectuais, afetivos, humanos, espirituais, sociais, para que o jovem seja impulsionado para o trabalho eficiente, melhorando sua qualidade de vida.

Nesse sentido, o papel da escola se destaca como local no qual a pessoa interage com os objetos de conhecimento para desenvolver capacidades que lhe permitam a integração na sociedade de modo a reproduzi-la. E o papel do professor, para complementar esse processo, é de animador que incentiva os alunos a construir os conhecimentos que são de seu interesse.

Essa concepção de formação integral é de base idealista. Segundo Vieira Pinto (1969), no idealismo, as ideias e o mecanismo que torna compreensível a realidade são absolutos, seja porque é parte da constituição inata do sujeito, seja porque são produtos de alguma experiência. Assim, as leis do pensamento são as leis da realidade circundante.

Ao contrário, a formação integral proposta nas Diretrizes da Educação Profissional está inspirada em Gramsci (2001) que se respalda no materialismo histórico dialético. Essa concepção defende que a criação do gênero humano se assenta no trabalho, ou seja, o trabalho cria o próprio homem. Por meio do trabalho, os homens criam instrumentos que modificam a sua constituição enquanto seres humanos. Assim, o trabalho é produto e processo de criação do homem.

De acordo com essa concepção, a formação dos homens se dá pela apropriação dos conhecimentos produzidos pela humanidade. Segundo Silva e Eidt (2010), a escola por objetivo, através do trabalho intencional com os conhecimentos sistematizados, tornar o aluno capaz de realizar novas teorizações sobre o real para que possa fazer interferências que levem às transformações necessárias. O papel que o professor exerce nesse processo é intencional,

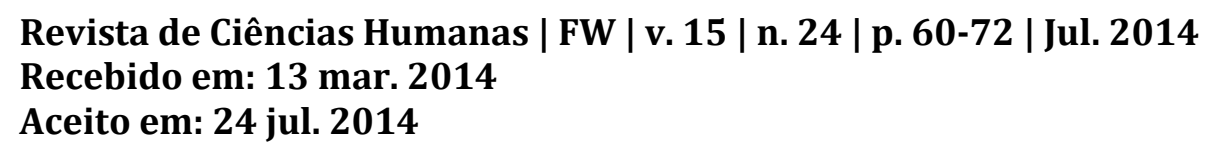


deliberado e planejado, de forma que sua mediação favoreça a apropriação, por parte dos alunos, dos conhecimentos social e historicamente produzidos.

A Formação Integral pressupõe a omnilateralidade, ou seja, o ser humano como ser real em condições objetivas de existência que se constitui no e pelo trabalho. Ou seja, o homem na produção da vida social, produz o mundo material, as relações sociais e as qualidades humanas correspondentes.

Essa concepção que inspira as Diretrizes Curriculares da Educação Profissional é de base materialista, pois parte do pressuposto de que não é a consciência que determina a realidade, mas as condições concretas de existência que determinam a consciência humana.

No quadro 1 apresenta características que sintetizam as concepções teóricas da Formação Integral que inspiram a Pedagogia da Alternância e das Diretrizes Curriculares da Educação Profissional:

QUADRO 1- SÍNTESE DAS BASES TEÓRICAS DA FORMAÇÃO INTEGRAL

\begin{tabular}{|c|c|}
\hline \multicolumn{2}{|c|}{ FORMAÇÃO INTEGRAL } \\
\hline PEDAGOGIA DA ALTERNÂNCIA & $\begin{array}{c}\text { DIRETRIZES CURRICULARES DA EDUCAÇÃO } \\
\text { PROFISSIONAL }\end{array}$ \\
\hline visão idealista & visão materialista \\
\hline unilateralidade & omnilateralidade \\
\hline adaptação ao modelo vigente & crítica ao modelo vigente \\
\hline aprender a aprender & apropriação do conhecimento \\
\hline integração ao processo produtivo & trabalho como princípio educativo \\
\hline mercado de trabalho & mundo do trabalho \\
\hline escola com interesses práticos imediatos & escola formativa, "desinteressada" \\
\hline
\end{tabular}

Fonte: síntese realizada pelas autoras

Através do quadro 1 se observa que as concepções de Formação Integral se distanciam porque possuem bases epistemológicas divergentes. Consequentemente, produzem diferentes práticas pedagógicas, mas que estão de alguma forma presentes nas Casas Familiares do Estado do Paraná.

\section{CONSIDERAÇÕES FINAIS}

Nessa investigação buscou-se refletir sobre as concepções de Formação Integral presentes nas Casas Familiares Rurais do Paraná.

O trabalho desenvolvido nas CFRs se pauta na Pedagogia da Alternância, que surge para atender as necessidades dos jovens do campo. Seus principais objetivos são contribuir Revista de Ciências Humanas | FW | v. 15 | n. 24 | p. 60-72 | Jul. 2014 
para o desenvolvimento integral do jovem e para o desenvolvimento do local onde vive. Por outro lado, as CFRs recebem orientações da Secretaria de Estado da Educação que produziu coletivamente com os professores da rede de ensino, documentos que devem orientar a prática escolar. Esta tem como principais objetivos a socialização dos conhecimentos produzidos ao longo da história e o desenvolvimento integral do ser humano numa perspectiva omnilateral.

Percebe-se nas concepções apresentadas certo distanciamento.

A Pedagogia da Alternância, através de uma diversidade de elementos específicos, busca desenvolver conhecimentos através do diálogo dos saberes para que o jovem assuma o compromisso com seu meio, forme sua personalidade e se capacite para a ação.

Por outro lado, as Diretrizes do Estado do Paraná apontam para a necessidade da formação integral do jovem, na perspectiva de desenvolver seus vários aspectos constitutivos com a finalidade de produzir as condições necessárias à existência, de modo que as contradições sejam explicitadas e superadas.

O assunto não se esgota aqui. Ao contrário, pretende suscitar discussões para que novos estudos e reflexões sejam realizados, contribuindo para o desenvolvimento da temática.

\begin{abstract}
This text is the result of discussions and studies conducted by Federal Technological University of Paraná campus Pato BrancoPost Graduate Program in Regional Development - Campus Pato Branco, and aims to reflect on the concepts of Integral Education present in the Rural Family Houses in Paraná State. In this sense, this article seeks to understand the concept of integral education that sustains the Alternation Pedagogy, practiced in Rural Family Houses, and to analyze whether this approach approximates or moves away from the conception explained by the Professional Education Guidelines of Paraná State. This reflection is very important because the professionals who work in the Paraná Rural Family Houses have to put the assumptions underlying the Alternation Pedagogy into practice, while following state curriculum guidelines for Professional Education. After the explanation of the concepts of Integral Education in Alternation Pedagogy and in Professional Education Guidelines, this article analyzes the epistemological foundations that sustains both guidance mentioned here and concludes that they are far apart because the first is located in idealists bases, and the second, in materialistic bases.
\end{abstract}

Keywords: Integral Education. Alternation Pedagogy. Rural Family Houses.

RESUMEN: Este trabajo es el resultado de debates y estudios efectuados en el Programa de Postgrado en Desarrollo Regional de la Universidad Tecnológica Federal do Paraná, campus Pato Branco. Tiene como objetivo reflexionar sobre los conceptos de formación integral presentes en las Casas Familiares Rurales del Estado de Paraná.Trata de comprender el concepto de educación integral que apoya la Pedagogía de la Alternancia practica en casas rurales familiares, y analizar si es cerca o lejos de la concepción se explica en las Directrices de Educación Profesional del Estado de Paraná. Esta reflexión es de suma importancia debido

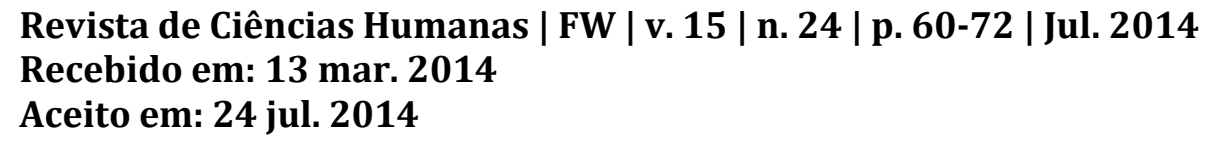


a que los profesionales que trabajan en la Casa Familiar Rural de Casas Paraná tienen la orientación para poner en práctica los supuestos que subyacen a la Pedagogía de la Alternancia, siguiendo las directrices del plan de estudios del Estado. Tras exponer los conceptos de formación integral en Pedagogía de la Alternancia y Directrices para la educación profesional, se analizan los fundamentos epistemológicos que sostienen y concluyen que se alejan debido a que el primero se encuentra en las bases idealistas y segundo en bases materialistas.

Palabras clave: Formación Integral. Pedagogía de la Alternancia. Familia Rurales.

\section{REFERÊNCIAS}

AMBROSIO, Teresa. A Formação entre o Desenvolvimento Sustentável e o Desenvolvimento Humano. In: II Seminário Internacional da Pedagogia da Alternância. Pedagogia da Alternância: Formação em Alternância e Desenvolvimento Sustentável. Brasília: UNEFAB, 2002. p. 20-32.

ESTEVAM, Dimas O. Casa Familiar Rural: a formação com base na pedagogia da alternância. Florianópolis: Insular, 2012.

GALLO, Silvio. A educação integral numa perspectiva anarquista. In: COELHO, Ligia M. C da C.; CAVAliERE, Ana Maria C. V (Orgs.). Educação brasileira em tempo integral. Petrópolis: Vozes, 2002, p.7-42.

GARCIA-MARIRRODRIGA, Roberto; CALVÓ, Pedro P. Formação em alternância e desenvolvimento local: o movimento educativo dos CEFFA no mundo. Belo Horizonte: $\mathrm{O}$ Lutador, 2010.

GIMONET, Jean Claude. Praticar e compreender a Pedagogia da Alternância dos CEFFAs. Petrópolis, RJ: Vozes, Paris: AIMFR - Associação Internacional dos Movimentos Familiares e de Formação Rural, 2007.

GRAMSCI, Antonio. Cadernos do cárcere. v. 2. 4 ed. Rio de Janeiro: Civilização Brasileira, 2001.

GRAMSCI. Antonio. Os intelectuais e a organização da cultura. Rio de Janeiro: Civilização Brasileira. 1968.

MANACORDA, Mario A. O princípio educativo em Gramsci. Campinas, SP: Alínea, 2008.

PARANÁ. Secretaria de Estado da Educação. Diretrizes da Educação Profissional: fundamentos políticos e pedagógicos. Curitiba: SEED, 2006.

PEREIRA, Erialdo A. Avaliação formativa e Pedagogia da Alternância: uma experimentação pedagógica na Escola Família Agrícola do Porto Nacional (TO). Revista da formação por alternância, v. 1, n. 1, p. 56-77, 2005.

PIAGET, Jean. Para onde vai a Educação? Rio de Janeiro: José Olympio, 1977.

Revista de Ciências Humanas | FW | v. 15 | n. 24 | p. 60-72 | Jul. 2014

Recebido em: 13 mar. 2014

Aceito em: 24 jul. 2014 
ROCHA, I. X. O. A formação integral nos CEFFAs. Revista da formação por alternância. v. 1, ano 3, n. 5, p. 5-18, 2007.

SAVIANI, Dermeval. Trabalho e educação: fundamentos ontológicos e históricos. Revista Brasileira de Educação, v. 12, n. 34, , p.152-180, jan./abr. 2007.

SILVA, Graziela L. R. da; EIDT, Nadia M. Oposições teórico-metodológicas entre a Psicologia Histórico-Cultural e o Construtivismo Piagetiano: implicações à educação escolar. In: PARANÁ. SECRETARIA DE ESTADO DA EDUCAÇÃO. Organização do trabalho pedagógico. Curitiba: SEED-PR, 2010, p. 111-128.

VIEIRA PINTO, A. Ciência e existência. Rio de Janeiro: Paz e Terra, 1969. 